\title{
An overview of assessment of prognostic and predictive factors in breast cancer needle core biopsy specimens
}

\author{
E A Rakha, I O Ellis
}

J Clin Pathol 2007;60:1300-1306. doi: 10.1136/icp.2006.045377

Needle core biopsy (NCB), as part of triple assessment for preoperative evaluation and diagnosis of breast cancer, is now considered as an established, highly accurate method for diagnosing breast cancer that has replaced either fine needle aspiration cytology or excisional biopsy as the initial diagnostic biopsy procedures in many institutions. In addition to its primary role in establishing an accurate histological diagnosis, NCB can potentially provide important additional pathological prognostic information which may be of direct clinical value in certain situations, such as patients being considered for preoperative (neoadjuvant) therapy. With this background in mind we briefly review the current role of NCB in breast cancer diagnosis and then concentrate this review on the usefulness and issues relating to use of this technique in providing accurate, reliable and clinically relevant preoperative prognostic and predictive information in patients with breast cancer.

See end of article for authors' affiliations

Correspondence to: Professor lan O Ellis, Molecular Medical Sciences, University of Nottingham, Department of Histopathology,

Nottingham City Hospital

NHS Trust, Hucknall Road, Nottingham NG5 1PB, UK; ian.ellis@nottingham.ac.uk

Accepted 28 June 2007 Published Online First 14 July 2007
S ince Bolmgren et al ${ }^{1}$ introduced stereotactic needle biopsy of the breast in the late 1970s, and the introduction of automated core biopsy guns in the mid 1990s, needle core biopsy (NCB) has become an increasingly important diagnostic tool in the assessment of both palpable and non-palpable breast lesions. ${ }^{2}{ }^{3}$ NCB is now considered the method of choice for tissue sampling as part of the triple assessment of breast disease, ${ }^{4}$ and the published data suggest that the use of core biopsy has increased the preoperative diagnosis rate in screen detected breast cancers. ${ }^{56}$ $\mathrm{NCB}$, as compared to preoperative fine needle aspiration biopsy, can reliably distinguish between in-situ and invasive cancers, allow evaluation of more histological, prognostic, and predictive factors in breast cancer, and provide ample tissue for ancillary testing such as immunohistochemical studies (IHC), DNA and RNA analysis and other molecular techniques. In some patients with breast cancer, for example those treated with preoperative chemotherapy, the NCB specimen might be the only pretreatment tissue sample available for studies of prognostic and predictive markers. Moreover, NCB specimens can be evaluated easily by histopathologists to whom H\&E stained sections are familiar. ${ }^{7}$

$\mathrm{NCB}$ can be performed either freehand or with image guidance. Initial use of image guided NCB was reported with the utilisation of stereotactic imaging and extended to ultrasound-guided biopsies that facilitated biopsy of the clinically occult lesions. These biopsy specimens can be collected with automated (spring-activated) needle core or vacuum assisted biopsy device. However, the biopsy method used depends on which modality best depicts the abnormality, location and size of the abnormality within the breast, patient factors, and the operator's experience and preference.

\section{DIAGNOSTIC ACCURACY OF NCB}

The diagnostic accuracy of NCB has been intensely verified and several studies have shown good concordance between NCB and subsequent surgical excision biopsy for diagnosis of carcinoma (ranging from $91 \%$ to $100 \%$ )..$^{7-13}$ The sensitivity for detection of malignancy is high in the majority of published studies (85-100\%) and specificity is 96$100 \%$ for stereotactically guided $\mathrm{NCB},{ }^{8}{ }^{14-19}$ although a few studies have shown a lower rate of sensitivity $\left(\operatorname{eg} 71 \%^{20}\right.$ ) and specificity (eg $85 \%^{21}$ ). Slightly better results were documented in ultrasound-guided NCB and vacuum-assisted biopsies than in stereotactic, spring-loaded and freehand biopsies, ${ }^{12} 22-28$ and for diagnosis of palpable masses than for calcifications. ${ }^{28}$ However, the accuracy of NCB in the diagnosis of malignancy and the amount of information gained from it may be affected by several other factors, including basic definitions and methodology, case selection (palpable versus screen-detected lesion), ${ }^{29}$ needle size, ${ }^{30-33}$ number of cores taken, ${ }^{14}{ }^{19}{ }^{34-36}$ amount of clinical material obtained, ${ }^{37}$ presence of calcification on $\mathrm{NCB}^{33}$ level of expertise of the operator and breast pathologist, ${ }^{19}{ }^{38}$ and even timing of the biopsy..$^{39}$ For example, some authors have reported that one of the major problems with assessing pathological factors on NCB specimens is undersampling of the most informative areas ${ }^{40}$; therefore, an adequate volume of biopsy material is recommended, particularly during sampling of tumours with large size and in cases of calcifications. ${ }^{22}{ }^{41}$ However, there are no available guidelines that indicate the number of cores or volume of tissues that should be obtained from tumours of certain size or with a specific amount of calcification. This should ideally be determined by common sense, and patient tailored. In our own clinic setting audit of ductal carcinoma in-situ (DCIS), diagnosis in patients presenting with mammographic calcification has shown that an optimum of either three or more cores containing calcium or five or more flecks of calcium in total is required to ensure adequate sampling of a calcification lesion. ${ }^{42}$ It is important that radiologists sampling breast lesions understand that both quality and 
Table 1 Concordance rate between needle core biopsies and subsequent surgical specimens

\begin{tabular}{|c|c|c|c|c|c|c|c|c|c|}
\hline Authors & No. & $\begin{array}{l}\text { Grade } \\
(\%)\end{array}$ & $\begin{array}{l}\text { Tubule } \\
\text { formation (\%) }\end{array}$ & $\begin{array}{l}\text { Nuclear } \\
\text { pleomorphism } \\
\text { (\%) }\end{array}$ & Mitosis (\%) & $\begin{array}{l}\text { Tumour type } \\
\text { (\%) }\end{array}$ & ER (\%) & $\operatorname{PgR}(\%)$ & HER2 $(\%$ \\
\hline Usami et al $(2007)^{68}$ & 111 & 75 & & & & 83 & 95 & 88 & 88 \\
\hline Cahill et al $(2006)^{51}$ & 95 & 77 & & & & 98 & 68 & 71 & 60 \\
\hline Burge et al $(2006)^{52}$ & 87 & 77 & & & & 100 & 95 & 89 & 96 \\
\hline Hodi et al $(2007)^{105}$ & 338 & & & & & & 99 & & \\
\hline Badoual et al $(2005)^{24}$ & 110 & 73.1 & & & & 74 & 90 & 89. & \\
\hline Usami et al $(2005)^{45}$ & 22 & 80 & & & & 89 & 100 & 95 & 80 \\
\hline Monticciolo $(2005)^{46}$ & 288 & $\begin{array}{l}77 \text { nudl } \\
74 \mathrm{com}\end{array}$ & $\begin{array}{l}\text { ar grade } \\
\text { ined grade }\end{array}$ & & & & & & \\
\hline Al Sarakbi et al $(2005)^{102}$ & 93 & & & & & & 95 & 89 & \\
\hline Mann et al $(2005)^{53}$ & 100 & & & & & & 86 & 83 & 80 \\
\hline Deshpande et al $(2005)^{57}$ & 105 & 75 & & & & 96 & & & \\
\hline $\mathrm{O}^{\prime}$ Leary et al $(2004)^{37}$ & 113 & 62 & 56 & 57 & 59 & 65 & & & \\
\hline Andrade and Gobbi $(2004)^{59}$ & 120 & 59 & 55 & 58.9 & 62 & 67 & & & \\
\hline Harris et al $(2003)^{40}$ & 500 & 67 & 82 & 73 & 58 & 74 & & & \\
\hline Connor et al $(2002)^{106}$ & 44 & 64 & & & & & 98 & 82 & 91 \\
\hline Mclntosh et al (2002) ${ }^{44}$ & 133 & 91 & & & & 84 & & & \\
\hline Shannon et al $(2001)^{43}$ & 734 & $\begin{array}{l}75 \mathrm{grac} \\
70 \mathrm{grac} \\
86 \mathrm{grac}\end{array}$ & & & & 94 & & & \\
\hline Sharifi et al (1999) ${ }^{47}$ & 79 & 75 & & & & 81 & & & \\
\hline Gotzinger et al (1998) & 150 & 84 & & & & 100 & 97 & 91.3 & \\
\hline Jacobs et al $(1998)^{108}$ & 56 & & & & & & 100 & & 100 \\
\hline Di Loreto et al (1996) & 41 & 80 & & & 76 & & 78 & 80 & 90 \\
\hline Dahlstrom et al $(1996)^{7}$ & 51 & 69 & & & & 78 & & & \\
\hline Baildam ef al (1989) & 140 & 69 & & & & & & & \\
\hline
\end{tabular}

$E R$, oestrogen receptor; PgR, progesterone receptor.

quantity of tissue sampled are important to achieve high levels of sensitivity and specificity in needle core biopsy non-operative diagnosis.

\section{EVALUATION OF PROGNOSTIC AND PREDICTIVE FACTORS OF BREAST CARCINOMA ON NCB}

NCB is thus considered to be a highly accurate method of obtaining a preoperative histological diagnosis of breast cancer. There is dispute, however, about the range of prognostic and predictive information that should be obtained from NCB and included in the pathology report. Pathological prognostic and predictive factors are used in clinical practice for a variety of reasons. They provide detailed information on the prediction of outcome and response to therapy of an individual patient as a basis for accurate pretreatment planning of preoperative (neoadjuvant), operative and postoperative (adjuvant) therapy.

There are still insufficient data available at present to allow a consensus on what are reasonable performance goals for core biopsy diagnosis. ${ }^{43}$ However, it has been reported that once the diagnosis of malignancy is made on NCB, and when there is sufficient tissue, the following pathological features could be clearly identified in the pathology report. For invasive cancer: tumour type, histological grade, the presence, or absence of coexistent in-situ and microinvasive carcinoma and the relative contribution of the in-situ and invasive components. Additional histological prognostic information includes lymphovascular invasion, true tumour size $\mathrm{e}^{43-47}$ and presence and extent of tumour necrosis. ${ }^{48}$ For DCIS: the extent of the in-situ component, architectural type (eg, comedo, cribriform, and so forth) and nuclear grade..$^{40}$ Other prognostic and predictive features that could be included in the pathology report are the immunophenotype of the tumour, ${ }^{24} 43{ }^{45} 5^{51-53}$ such as oestrogen (ER) and progesterone (PgR) receptor and HER2 status. When sufficient tissue is present for evaluation, other biomarkers may be included such as markers of proliferation, oncogene/tumour suppressor gene assessment, tumour DNA content, cytokeratin phenotype (basal versus luminal) and in the future, potentially any other available ancillary tests that can be performed on formalin-fixed paraffin embedded tissue.

\section{HISTOLOGICAL PROGNOSTIC FACTORS Tumour type}

Tumour type has been shown to be a prognostic factor in breast cancer. ${ }^{54}$ Histological typing of invasive breast tumours is carried out on well fixed samples and involves the assessment of several blocks to determine all of the features present. The evaluation of a variety of features including the extent of tubule formation, the presence of lymphoid stroma, mucin production, syncytial or discohesive growth pattern, and "Indian file" formation allows tumours to be separated according to type.

NCB can accurately predict histological type in the great majority of cases, with a rate of concordance with the full surgical specimen ranging from 93\% to $100 \%{ }^{43} 51525556$ However, lower figures have also been reported (table 1). NCB is particularly accurate when predicting the presence of pure pathological types, such as tubular, lobular medullary-like and mucinous carcinoma, ${ }^{5156}$ although the possibility of a mixed tumour cannot be ruled out. ${ }^{57} \mathrm{~A}$ common problem with attempting to ascribe tumour type on NCB is the confusion between tubular mixed (or tubular variant) carcinomas and invasive duct/no special type carcinoma. ${ }^{58}$ Some authors have also reported that it is sometimes difficult to differentiate between invasive ductal and lobular carcinoma. ${ }^{75157}$ This is most probably the result of sampling error and tumour heterogeneity which may result in obtaining a sample that is not representative of the tumour as a whole. As NCB analysis reflects the characteristics of the area of the primary tumour that it has sampled, its sensitivity in comparison to the overall full surgical specimen may be affected by regional differences in the structure and differentiation of the primary tumour. ${ }^{59} 60$

\section{Tumour grade}

Histological grade is an important and well-established prognostic factor in breast cancer. ${ }^{61-63}$ Although different grading systems have been used to assess tumour grade, it has been 
reported that Nottingham modification of the Bloom and Richardson method, ${ }^{61}$ in which tubule formation, nuclear pleomorphism, and mitotic frequency are evaluated, gives reproducible results and correlates well with survival. ${ }^{64-67}$ Current evidence shows that grading on core biopsy can be performed and appears straightforward because formalin fixation is likely to be optimum. Concordance between grade on core biopsy and that in the definitive excision specimen can be achieved in approximately $75 \%$ of cases, varying in different

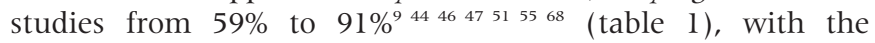
highest level of agreement achieved in grade 3 carcinomas. ${ }^{40}$

Most of the discrepancy was that the surgical materials tended to be higher grade (upgrade) than NCB, almost invariably by only one level. ${ }^{46}{ }^{69}$ Therefore, care should be taken with interpretation of the grade on NCB as this might result in some patients who would benefit from receiving neoadjuvant treatment for high-grade tumours being excluded. Although the exact reason is not clear, several factors may contribute to this grade disagreement between NCB and surgical specimens, including the following: (1) sampling only a small proportion (under-sampling) of a heterogeneous tumour ${ }^{59} ;(2)$ presence of an insufficient amount of tumour in the core to allow 10 high power fields to be counted for mitosis; (3) in surgical specimens, mitotic figures are counted in the periphery of the tumour, the growing edge of the tumour, where they are more frequent; (4) there is evidence that the observed mitotic count may be lower in the core biopsy than in the excision specimen, resulting in a systematic bias leading to underscoring overall grade on NCB..$^{240} 70$ In our own experience this latter issue is the main cause of discrepancy between NCB grade and final grade derived from examination of the surgical specimen. It is most probably due to traumatic damage of cells in the fragile state of mitosis obscuring their visibility in H\&E stained sections. To date no effective routinely applicable alternatives have emerged for identification or scoring of mitosis frequency or growth fraction in core biopsy samples.

\section{Tumour size}

Tumour size is another well-established time dependent prognostic factor in breast cancer. ${ }^{71}{ }^{72}$ In a comparison study between NCB and subsequent excision specimens from 79 women with invasive breast cancer, Sharifi et al ${ }^{47}$ found a significant correlation between tumour size on NCB and excision specimens $\left(r^{2}=0.30, p=0.01\right)$; however, the pathological T stage was underestimated on NCB in $79 \%$ of cases and the $\mathrm{T}$ substage was underestimated on $\mathrm{NCB}$ in $71 \%$ of $\mathrm{Tl}$ lesions. ${ }^{47}$ Although on NCB, an approximate evaluation of the minimum size of the tumour may be made, measurement of this parameter on NCB is not recommended as a routine practice. $^{60}$ If a preoperative estimate of size is required, this should be performed ultrasonographically. ${ }^{73}$

\section{IN-SITU COMPONENT}

Previous studies of the accuracy of NCB have addressed the ability of NCB to detect in-situ disease in both non-palpable mammographically detected lesions ${ }^{2835}$ and in palpable tumours. $^{256}$ These studies have shown that the accuracy was lower for diagnosis of DCIS than for invasive disease. ${ }^{24} 29457475$ In addition, a serious problem may arise when a diagnosis of pure DCIS is made on NCB, but an associated invasive component is identified in the subsequent surgical excision specimen, raising the possibility of lymph node metastasis. $^{7243256}$ If lymph node biopsy is not performed at the time of the definitive operative procedure of these cases, patients found to have an invasive cancer will require a second operative staging procedure. For example, in a previous study of 103 cases of pure DCIS diagnosed by NCB, Yen et $a l^{76}$ found that $10 \%$ of these patients had a positive sentinel lymph node.
The invasive component may be underestimated on NCB with a diagnosis of pure DCIS in 15-20\% of cases. ${ }^{1068}{ }^{77-79}$ In addition, Mendez et $a l^{80}$ have identified microinvasive carcinomas in $8 \%$ of cases $(6 / 77)$ diagnosed as pure DCIS on NCB. The number of DCIS upgraded to invasive carcinomas in surgical biopsies may be related to a variety of histopathological and radiological reasons. This upgrading of DCIS is more likely where there is high-grade DCIS, ${ }^{76}{ }^{79-83}$ presence of periductal inflammation ${ }^{81}$ or lobular cancerisation, ${ }^{79}$ increasing number of calcifications, $^{82}$ comedonecrosis with a cribriform/papillary pattern, and NCB from a palpable mass or large-sized lesions. ${ }^{76-79}$ 83-86 DCIS underestimation rates also appeared to be in inverse proportion to the total volume of tissue examined (number of cores and needle gauge size). ${ }^{78} 87$ It is important when making a diagnosis of DCIS in NCB from a palpable mass to remember that most breast tumours exceeding $1.0 \mathrm{~cm}$ in size are at least partially invasive, especially when they are palpable. ${ }^{88}$ In our experience the underestimation of presence of invasion can be reduced by use of ultrasound guided biopsy targeting mass lesions if present and by use of multiple cores samples or larger volume vacuum assisted tissue sampling methods. This approach is supported by data indicating that the level of underestimation may be affected by the gauge of the needle and it has been suggested that this incidence can be reduced by using a thicker needle core. ${ }^{32}$ Lee et al ${ }^{50}$ have reported that an 11-gauge vacuum-assisted biopsy was as reliable as open surgical biopsy for diagnosing DCIS without invasion. Previous studies have reported that the incidence of DCIS underestimates was $20-30 \%$ using a 14-gauge core, ${ }^{74} 8089$ 4-10\% with an 11-gauge core, 228490 and 4\% using 8-gauge stereotactic vacuum-assisted biopsy. ${ }^{84}$ It is worth mentioning, however, that some authors could not identify any factor capable of predicting a higher likelihood of an invasive focus in surgical specimens following a diagnosis of DCIS by NCB, ${ }^{75} 89$ and recommended that patients with DCIS diagnosed by core biopsy should be offered sentinel lymph node biopsy.

It has also been reported that a smaller lesion size, ${ }^{74}$ and lowgrade DCIS $^{74}$ may be associated with increased risk for a negative or non-diagnostic core in patients with DCIS; the main reason for a false positive diagnosis of DCIS in NCB is atypical ductal hyperplasia (14-30\% of cases), ${ }^{28} 9192$ and in particular if the suspected lesion is restricted to one or two foci. ${ }^{93}$ On the other hand, most cases of DCIS in NCB which are suspicious or positive for microinvasion will demonstrate invasion in the subsequent excision. ${ }^{83}$ Thus, these cases should accordingly be carefully evaluated and we would recommend diligent examination of the core biopsy sample at multiple levels in such cases; if a definite diagnosis cannot be made, a surgical excision is recommended. In fact, the underestimation of malignancy in NCB and the role of atypical ductal hyperplasia is best reviewed in the article published Houssami et al, ${ }^{86}$ who concluded, for instance, that a reliable diagnosis of atypical ductal hyperplasia may not be possible with NCB, because criteria for its diagnosis are based on surgical resection specimens.

After a diagnosis of DCIS is made on NCB, several other related variables should be addressed, such as extent of DCIS and its relative proportion to invasive component, nuclear grade, architecture, and the presence of necrosis and associated calcification. ${ }^{70}$ The combination of nuclear grade and presence of necrosis is currently the best predictor of biological behaviour of DCIS. ${ }^{94}$ Assessment of the presence and extent of DCIS component in a small invasive carcinoma is particularly important for breast conservation as patients whose tumours are predominantly in-situ, or which contain a significant in-situ component $(>25 \%)$ and with evidence of DCIS outside of the invasive growth, are defined as having extensive intraductal carcinoma, a status that can adversely affect local control if the 
in-situ component is not adequately resected. Some of these patients with otherwise small carcinomas favourable for breast conservative therapy will not be candidates for breast conservation..$^{23}$ In a previous study of DCIS in clinically palpable T3 and larger T2 carcinomas, El-Tamer et $a^{56}$ reviewed whether NCB can identify patients with purely or predominantly in-situ carcinomas. They showed that NCB can reliably determine whether a palpable tumour mass is predominantly invasive or in-situ and accurately identify the probable extent of DCIS within an invasive mass. The authors also demonstrated a very high level of concordance between histological subtype, tumour grade, and the percentage of DCIS present in NCB and subsequent surgical biopsies.

Grading and histological typing of DCIS on core biopsy can be performed and is reasonably accurate. Current evidence suggests that concordance between DCIS grade on NCB and that in the definitive excision specimen is slightly similar to that of invasive tumours. In our institution, we found a concordance rate of $65 \%$ for DCIS grade compared to $67 \%$ for invasive tumour grade. ${ }^{40}$ Others have reported slightly better agreement for DCIS grade than for invasive grade. ${ }^{56}$

\section{MICROINVASIVE CARCINOMA}

Although minimally invasive "microinvasive" carcinoma $(\leqslant 0.1 \mathrm{~cm})$ of the breast is a well-known and well-characterised entity in excision specimens, it is a rare finding in breast NCB and may require relatively extensive sampling to identify. Microinvasive carcinoma in NCB is commonly associated with DCIS and is often associated with larger invasive foci at excision. In a large series of NCB, Renshaw ${ }^{95}$ identified microinvasive carcinoma in $1 \%$ of cases (16/8500). The surgical specimens of these cases showed invasive carcinomas in 11 cases ( 2 with positive lymph nodes) and DCIS alone in 4 cases. Therefore, the term "microinvasive" carcinoma, like "DCIS", should be used with care on NCB, and clinicians should be aware that there is a high probability of underdiagnosis of invasion.

\section{LYMPHOVASCULAR INVASION}

Lymphovascular invasion (VI) is another important prognostic factor in breast cancer. The presence of histologically confirmed VI is associated with an increased risk of metastatic disease, increased risk of local recurrence, and reduced survival. ${ }^{96}$ Some authors reported the inability of NCB to detect VI accurately. ${ }^{45} 58$ For example, Sharifi et a ${ }^{47}$ found that none of the 17 cancers with VI in the excision specimen showed VI on the NCB. However, in a study of 500 cases of invasive carcinoma diagnosed by NCB, we found that the concordance rate of detection of VI between NCB and surgical specimens was $69 \%{ }^{40}$ Our result was supported by the study of $\mathrm{Pu}$ et $\mathrm{al}^{48}$ who assessed VI in the preoperative NCB to measure the pathological response after neoadjuvant chemotherapy; they were able to detect VI in NCB and found that its presence in NCB was associated with axillary lymph node metastases. They suggested that the presence of VI in NCB is an important feature that should be included in the standard report. In practical terms, when VI is identified in a needle core biopsy sample it should be reported as it may influence surgical management. There is, however, a significant failure rate of identification of at least $30 \%$ due to its microfocal nature.

\section{TUMOUR NECROSIS}

Assessment of necrosis in NCB may be useful in at least two settings: (1) intralumenal necrosis is one of the main features for diagnosis and grading of DCIS and is a pathological predictive factor for recurrence $709798 ;(2)$ assessment of necrosis can also help to predict and monitor pathological response to neoadjuvant chemotherapy. ${ }^{48}$

\section{LYMPH NODE STAGE}

It is well established that the lymph node stage is one of the most important prognostic factors for patients with breast cancer. Although there is little available data, in a previous study that included 166 patients presenting with primary operable breast cancer, we have shown that ultrasound-guided $\mathrm{NCB}$ and routine sectioning can identify lymph node disease in a relatively high percentage of cases $(80 \%(27 / 34)$ of the sampled abnormal nodes). ${ }^{99}$ In a more recent study, NCB of the sentinel lymph node has been shown to be as accurate as excisional biopsy in detecting lymph node positivity by routine serial sectioning and H\&E staining. ${ }^{100}$

\section{BIOMARKER ASSESSMENT}

In addition to histological information, NCB can be used to study the status of molecular markers with prognostic and predictive value that can contribute to an optimal selection of treatment strategy, especially for patients who may undergo preoperative therapy. The assessment of hormone receptors (HR) can be performed on NCB and correlates well with subsequent surgical excision specimens ${ }^{45101}$ (table 1). The concordance rate was found to be higher for ER than PgR, which could be due to the fact that ER are more homogeneously distributed. ${ }^{16} 102103$

It has been reported that HR scores correlated best in specimens that stain strongly and moderately positive; most discrepancies were between weakly positive and negative cases. Similar findings were reported in surgical specimens in which the major area of difficulty of reproducibility of HR staining was the group with low expression. In such cases, there is a risk of false negative results, mainly due to inadequate IHC assay sensitivity. ${ }^{104}$ When comparisons are made, NCB tends to upscore the receptor stain intensity compared with the subsequent surgical specimen, and in some cases, the cores show positive staining, while the surgical specimens are negative..$^{5153} 105106$ Therefore, HR assays on NCB appears to be more reliable than assays on surgical specimens; better fixation on the core is the most likely explanation. Some authors, therefore, recommend that IHC for HR should be performed on core biopsy specimens, to ensure that patients with HR positive cancers receive appropriate hormonal therapy and are not overtreated with systemic chemotherapy. ${ }^{53}$ In our institution, we routinely assess ER in the core biopsy for invasive carcinomas. We repeat staining in the surgical specimen if the core biopsy shows weak staining or if the tumour shows morphological heterogeneity in the surgical resection and was ER negative on the core biopsy. ${ }^{105}$

HER2 status is recognised in breast carcinoma as a prognostic marker; overexpression is associated with worse prognosis. More importantly, testing is now required as a prerequisite to predict drug response and to select patients for trastuzumab treatment. Several reports have shown that the assessment of HER2 status on NCB in breast cancer is accurate and reliable. ${ }^{4152107} 108$ In a previous study of 325 patients with primary breast cancer, Taucher $e t a l^{109}$ investigated the accuracy of HER2 status using IHC and fluorescence in-situ hybridisation (FISH) on NCB and compared the result with surgically obtained specimens. They found that the accuracy of IHC assessment of HER2 in NCB was $92 \%$ and increased to $96 \%$ with additional FISH analysis, which was applied to strongly positive cases. Therefore, they recommended performing FISH analysis for cases with strong IHC positivity on NCB in order to minimise the number of false-positive results.

In addition to HR and HER2 outlined above, a wide range of other molecular markers that have been identified in breast 
cancer, can be reliably assessed on NCB. For example, p53 and bcl2, ${ }^{107}{ }^{108}$ MIB-1, ${ }^{106}{ }^{107}$ EGFR, ${ }^{106}$ and human milk fat globule membrane ${ }^{16}$ have been evaluated on NCB; their assessment was proved to be accurate and reliable with a concordance rate of 85-100\% when compared to surgical specimens. The accuracy of these markers was reported to be higher when they were scored as dichotomous variables (positive Vs negative expression) rather than as continuous variables, possibly due to intratumoural cell heterogeneity. ${ }^{108} 110$ In addition, other markers can be reliably applied on NCB, such as E-cadherin to distinguish lobular from ductal carcinomas on NCB, myoepithelial markers (eg CK5/6, CK14, p63, CD10 or SMA), to differentiate between in-situ and invasive lesion. Interestingly, assessment of E-cadherin on NCB may also be relevant from the radiological perspective, as there are some indications that preoperative magnetic resonance imaging evaluation is accurate in determining true tumour extent in invasive lobular carcinoma, ${ }^{111112}$ thereby impacting on the extent of therapeutic surgery.

\section{OTHER ANCILLARY STUDIES}

Estimation of microvessel density (MD) on NCB specimens in breast cancer may predict response to systemic therapy. Two previous studies have tried to assess MD on NCB and compare it with the subsequently excised tumours; however, both found that MD may not be reliably assessed on NCB and concluded that its usefulness, when measured as a continuous variable on NCB is limited. ${ }^{108} 113$

Gene expression data obtained from preoperative NCB of breast cancer patients can be used to build accurate predictive models that separate different molecular profiles. Several studies have shown the potential usefulness and reliability of NCB for high-throughput gene expression studies, such as semi-quantitative RT PCR, microarray technology and microRNAs (miRNAs) expression profiling. ${ }^{114} 115$ In addition, DNA analysis by flow cytometry was performed on NCB and the concordance with resected samples was high. ${ }^{16}$

\section{NEGATIVE SURGICAL EXCISION AFTER NCB}

Another important point, which merits mention in this review, is the pathological approach when NCB removes the entire tumour, and the therapeutic surgical excision is devoid of residual tumour. Although no guidelines are available so far, we consider the best approach is to make sure that, in the surgical specimen, the core biopsy sample site is present, has been completely sampled and is completely removed. If these criteria are satisfied, then it is safe to state that the invasive component (or in-situ lesion) has been removed by the NCB sampling process. In this circumstance, the characteristics of the tumour should be assessed on the needle core sample-size, grade, type, VI, ER, PgR, and HER2. Tumour size should be correlated with the imaging size and it may be prudent to record the imaging size as the true size of the lesion.

\section{CONCLUSION}

NCB can reliably provide useful preoperative prognostic and predictive information in breast cancer patients which can play a major role in planning treatment strategies. Presence of invasive tumour, tumour type, histological grade, presence and extent of DCIS (including its features such as architecture type and grade) and tumour necrosis and lymph node status, if sampled, can be assessed relatively reliably on NCB. Assessment of prognostic and predictive biomarkers such as ER, PgR, HER2, MIB- 1 and bcl2 and other ancillary tests can be performed on NCB and gives highly accurate results. Evaluation of vascular invasion, and minimal tumour invasion associated with DCIS may be less reliable. Primary tumour size and MD

\section{Take-home messages}

- Needle core biopsy (NCB) is now considered the method of choice for tissue sampling as part of the triple assessment of breast disease.

- NCB can reliably provide useful preoperative prognostic and predictive information in patients with breast cancer, which can play a significant role in planning treatment strategies.

- Presence of invasive tumour, histological tumour type, presence of ductal carcinoma in-situ, hormone receptor status and HER2 overexpression can be assessed reliably on NCB.

- Meticulous operator technique is essential to provide representative samples.

- Careful interpretation with prior knowledge of the limitations of the technique and adherence to principles of triple assessment following biopsy can improve the diagnostic accuracy of NCB.

measurement may give unreliable values and their assessment on surgical specimens should be considered. However, it is important to emphasise the following: (i) meticulous operator technique is essential to provide representative samples; (ii) careful interpretation with prior knowledge of the limitations of the technique; and (iii) adherence to principles of triple assessment following biopsy can improve the diagnostic accuracy of NCB and allow for early recognition of the majority of false-negative cases and eliminate discordant diagnoses.

\section{Authors' affiliations}

E A Rakha, I O Ellis, Molecular Medical Sciences, University of Nottingham, Department of Histopathology, Nottingham City Hospital NHS Trust. Nottingham University, Nottingham, UK

Competing interests: None declared.

\section{REFERENCES}

1 Bolmgren J, Jacobson B, Nordenstrom B. Stereotaxic instrument for needle biopsy of the mamma. AJR Am J Roentgenol 1977;129:121-5.

2 Pijnappel RM, van Dalen A, Borel Rinkes IH, et al. The diagnostic accuracy of core biopsy in palpable and non-palpable breast lesions. Eur J Radiol 1997;24:120-3.

3 Pettine S, Place R, Babu S, et al. Stereotactic breast biopsy is accurate, minimally invasive, and cost effective. Am J Surg 1996;171:474-6.

4 Pinder SE, Elston CW, Ellis IO. The role of pre-operative diagnosis in breast cancer. Histopathology 1996;28:563-6.

5 Litherland JC, Evans AJ, Wilson AR, et al. The impact of core-biopsy on preoperative diagnosis rate of screen detected breast cancers. Clin Radiol 1996;51:562-5.

6 Britton PD, Flower CD, Freeman AH, et al. Changing to core biopsy in an NHS breast screening unit. Clin Radiol 1997;52:764-7.

7 Dahlstrom JE, Jain S, Sutton T, et al. Diagnostic accuracy of stereotactic core biopsy in a mammographic breast cancer screening programme. Histopathology 1996;28:421-7.

8 Parker SH, Burbank F, Jackman RJ, et al. Percutaneous large-core breast biopsy: a multi-institutional study. Radiology 1994;193:359-64.

9 Di Loreto C, Puglisi F, Rimondi G, et al. Large core biopsy for diagnostic and prognostic evaluation of invasive breast carcinomas. Eur J Cancer 1996;32A: 1693-700.

10 Verkooijen HM, Peeters PH, Buskens E, et al. Diagnostic accuracy of large-core needle biopsy for nonpalpable breast disease: a meta-analysis. $\mathrm{Br} J$ Cancer 2000;82:1017-21.

11 Hoorntje LE, Peeters PH, Borel Rinkes IH, et al. Stereotactic large core needle biopsy for all nonpalpable breast lesions? Breast Cancer Res Treat 2002;73:177-82.

12 Dillon MF, Hill AD, Quinn CM, et al. The accuracy of ultrasound, stereotactic, and clinical core biopsies in the diagnosis of breast cancer, with an analysis of false-negative cases. Ann Surg 2005;242:701-7. 
13 Verkooijen HM. Diagnostic accuracy of stereotactic large-core needle biopsy for nonpalpable breast disease: results of a multicenter prospective study with 95\% surgical confirmation. Int J Cancer 2002;99:853-9.

14 Bassett L, Winchester DP, Caplan RB, et al. Stereotactic core-needle biopsy of the breast: a report of the Joint Task Force of the American College of Radiology, American College of Surgeons, and College of American Pathologists. CA Cancer J Clin 1997;47:171-90.

15 White RR, Halperin TJ, Olson JA Jr, et al. Impact of core-needle breast biopsy on the surgical management of mammographic abnormalities. Ann Surg $2001 ; 233: 769-77$

16 Baildam AD, Turnbull L, Howell A, et al. Extended role for needle biopsy in the management of carcinoma of the breast. Br J Surg 1989;76:553-8.

17 Ibrahim AE, Bateman AC, Theaker JM, et al. The role and histological classification of needle core biopsy in comparison with fine needle aspiration cytology in the preoperative assessment of impalpable breast lesions. J Clin Pathol 2001:54:121-5.

18 Yim JH, Barton P, Weber B, et al. Mammographically detected breast cancer Benefits of stereotactic core versus wire localization biopsy. Ann Surg 1996;223:688-700

19 Brenner RJ, Fajardo L, Fisher PR, et al. Percutaneous core biopsy of the breast: effect of operator experience and number of samples on diagnostic accuracy. AJR Am J Roentgenol 1996;166:341-6.

20 Dowlatshahi K, Yaremko ML, Kluskens LF, et al. Nonpalpable breast lesions: findings of stereotaxic needle-core biopsy and fine-needle aspiration cytology. Radiology 1991;181:745-50.

21 Israel PZ, Fine RE. Stereotactic needle biopsy for occult breast lesions: a minimally invasive alternative. Am Surg 1995:61:87-91.

22 Sebag $P$, Tourasse $C$, Rouyer N, et al. [Value of vacuum assisted biopsies under sonography guidance: results from a multicentric study of 650 lesions]. J Radiol 2006:87:29-34

23 Lagios MD. An expanded diagnostic role for core biopsy: assessment of the proportion of the duct carcinoma in situ component in invasive carcinomas. Ann Surg Oncol 1999;6:422-3.

24 Badoual C, Maruani A, Ghorra C, et al. Pathological prognostic factors of invasive breast carcinoma in ultrasound-guided large core biopsiescorrelation with subsequent surgical excisions. Breast 2005;14:22-7.

25 Chen SC, Yang HR, Hwang TL, et al. Intraoperative ultrasonographically guided excisional biopsy or vacuum-assisted core needle biopsy for nonpalpable breast lesions. Ann Surg 2003;238:738-42.

26 Houssami N, Ciatto S, Ambrogetti D, et al. Florence-Sydney Breast Biopsy Study: sensitivity of ultrasound-guided versus freehand fine needle biopsy of palpable breast cancer. Breast Cancer Res Treat 2005;89:55-9.

27 Berg WA, Gutierrez L, NessAiver MS, et al. Diagnostic accuracy of mammography, clinical examination, US, and MR imaging in preoperative assessment of breast cancer. Radiology 2004;233:830-49.

28 Fajardo LL, Pisano ED, Caudry DJ, et al. Stereotactic and sonographic largecore biopsy of nonpalpable breast lesions: results of the Radiologic Diagnostic Oncology Group V study. Acad Radiol 2004;1 1:293-308.

29 Frayne J, Sterrett GF, Harvey J, et al. Stereotactic 14 gauge core-biopsy of the breast: results from 101 patients. Aust N Z J Surg 1996;66:585-91.

30 Wong TE, Hisham AN. Core needle biopsy of palpable breast lump: the influence of needle size. Med J Malaysia 2003;58:399-404

31 Philpotts LE, Shaheen NA, Carter D, et al. Comparison of rebiopsy rates after stereotactic core needle biopsy of the breast with 11 -gauge vacuum suction probe versus 14-gauge needle and automatic gun. AJR Am J Roentgenol 1999; 172:683-7.

32 Cho N, Moon WK, Cha JH, et al. Sonographically guided core biopsy of the breast: comparison of 14-gauge automated gun and 11-gauge directional vacuum-assisted biopsy methods. Korean J Radiol 2005;6:102-9.

33 Margolin FR, Kaufman L, Jacobs RP, et al. Stereotactic core breast biopsy of malignant calcifications: diagnostic yield of cores with and cores without calcifications on specimen radiographs. Radiology 2004;233:251-4

34 Liberman L, Dershaw DD, Rosen PP, et al. Stereotaxic 14-gauge breast biopsy: how many core biopsy specimens are needed? Radiology 1994;192:793-5.

35 Jackman RJ, Nowels KW, Shepard MJ, et al. Stereotaxic large-core needle biopsy of 450 nonpalpable breast lesions with surgical correlation in lesions with cancer or atypical hyperplasia. Radiology 1994;193:91-5.

36 Dennison G. Anand R, Makar SH, et al. A prospective study of the use of fineneedle aspiration cytology and core biopsy in the diagnosis of breast cancer. Breast J 2003;9:491-3.

37 O'Leary R, Hawkins K, Beazley JC, et al. Agreement between preoperative core needle biopsy and postoperative invasive breast cancer histopathology is not dependent on the amount of clinical material obtained. J Clin Pathol 2004;57:193-5

38 Verkooijen HM, Peterse JL, Schipper ME, et al. Interobserver variability between general and expert pathologists during the histopathological assessment of large-core needle and open biopsies of non-palpable breast lesions. Eur J Cancer 2003;39:2187-91.

39 Macleod J, Fraser R, Horeczko N. Menses and breast cancer: does timing of mammographically directed core biopsy affect outcome? I Surg Oncol 2000;74:232-6.

40 Harris GC, Denley HE, Pinder SE, et al. Correlation of histologic prognostic factors in core biopsies and therapeutic excisions of invasive breast carcinoma. Am J Surg Pathol 2003;27:1 1-5.

41 Cavaliere A, Sidoni A, Scheibel M, et al. Biopathologic profile of breast cancer core biopsy: is it always a valid method? Cancer Lett 2005;218:1 17-21

42 Bagnall MJ, Evans AJ, Wilson AR, et al. When have mammographic calcifications been adequately sampled at needle core biopsy? Clin Radiol 2000:55:548-53.
43 Shannon J, Douglas-Jones AG, Dallimore NS. Conversion to core biopsy in preoperative diagnosis of breast lesions: is it justified by results? I Clin Pathol 2001;54:762-5.

44 Mclntosh SA, Panchalingam L, Payne S, et al. Freehand core biopsy in breast cancer: an accurate predictor of tumour grade following neoadjuvant chemotherapy? Breast 2002;11:496-500.

45 Usami S, Moriya T, Kasajima A, et al. Pathological aspects of core needle biopsy for non-palpable breast lesions. Breast Cancer 2005; 12:272-8.

46 Monticciolo DL. Histologic grading at breast core needle biopsy: comparison with results from the excised breast specimen. Breast J 2005;11:9-14.

47 Sharifi S, Peterson MK, Baum JK, et al. Assessment of pathologic prognostic factors in breast core needle biopsies. Mod Pathol 1999;12:941-5.

48 Pu RT, Schott AF, Sturtz DE, et al. Pathologic features of breast cancer associated with complete response to neoadjuvant chemotherapy: importance of tumor necrosis. Am J Surg Pathol 2005;29:354-8.

49 Mai KT, Yazdi HM, Ford JC, et al. Predictive value of extent and grade of ductal carcinoma in situ in radiologically guided core biopsy for the status of margins in lumpectomy specimens. Eur J Surg Oncol 2000;26:646-51.

50 Lee $\mathrm{CH}$, Carter D, Philpotts LE, et al. Ductal carcinoma in situ diagnosed with stereotactic core needle biopsy: can invasion be predicted? Radiology 2000;217:466-70

51 Cahill RA, Walsh D, Landers RJ, et al. Preoperative profiling of symptomatic breast cancer by diagnostic core biopsy. Ann Surg Oncol 2006;13:45-51.

52 Burge CN, Chang HR, Apple SK. Do the histologic features and results of breas cancer biomarker studies differ between core biopsy and surgical excision specimens? Breast 2006:15:167-72.

53 Mann GB, Fahey VD, Feleppa F, et al. Reliance on hormone receptor assays of surgical specimens may compromise outcome in patients with breast cancer. $J$ Clin Oncol 2005;23:5148-54.

54 Ellis IO, Galea M, Broughton N, et al. Pathological prognostic factors in breast cancer. II. Histological type. Relationship with survival in a large study with long term follow-up. Histopathology 1992;20:479-89.

55 Gotzinger P, Gebhard B, Gnant $M$, et al. [Value of punch biopsy in diagnosis of palpable breast tumors. A prospective analysis of 150 patients]. Chirurg 1998;69:1068-71.

56 El-Tamer M, Axiotis C, Kim E, et al. Accurate prediction of the amount of in situ tumor in palpable breast cancers by core needle biopsy: implications for neoadjuvant therapy. Ann Surg Oncol 1999;6:461-6.

57 Deshpande A, Garud T, Holt SD. Core biopsy as a tool in planning the management of invasive breast cancer. World J Surg Oncol 2005:3:1.

58 Denley H, Ellis IO, Elston CW. An audit of grading and typing of invasive breast carcinoma on needlecore biopsy specimens. J Pathol 1998; 186:ssPA10.

59 Andrade VP, Gobbi H. Accuracy of typing and grading invasive mammary carcinomas on core needle biopsy compared with the excisional specimen. Virchows Arch 2004;445:597-602.

60 Denley H, Pinder SE, Elston CW, et al. Preoperative assessment of prognostic factors in breast cancer. J Clin Pathol 2001:54:20-4.

61 Elston CW, Ellis IO. Pathological prognostic factors in breast cancer. I. The value of histological grade in breast cancer: experience from a large study with longterm follow-up. Histopathology 1991;19:403-10.

62 Elston CW, Ellis IO, Pinder SE. Pathological prognostic factors in breast cancer Crit Rev Oncol Hematol 1999;31:209-23.

63 Pinder SE, Murray S, Ellis IO, et al. The importance of the histologic grade of invasive breast carcinoma and response to chemotherapy. Cancer 1998:83:1529-39.

64 Latinovic L, Heinze G, Birner P, et al. Prognostic relevance of three histological grading methods in breast cancer. Int $J$ Oncol 2001;19:1271-7.

65 Sikka M, Agarwal S, Bhatia A. Interobserver agreement of the Nottingham histologic grading scheme for infiltrating duct carcinoma breast. Indian $J$ Cancer 1999;36:149-53.

66 Dalton LW, Page DL, Dupont WD. Histologic grading of breast carcinoma. A reproducibility study. Cancer 1994:73:2765-70.

67 Frierson HF Jr, Wolber RA, Berean KW, et al. Interobserver reproducibility of the Nottingham modification of the Bloom and Richardson histologic grading scheme for infiltrating ductal carcinoma. Am J Clin Pathol 1995;103:195-8.

68 Usami S, Moriya T, Amari M, et al. Reliability of prognostic factors in breast carcinoma determined by core needle biopsy. Jpn J Clin Oncol 2007;37:250-5.

69 Dahlstrom JE, Sutton S, Jain S. Histological precision of stereotactic core biopsy in diagnosis of malignant and premalignant breast lesions. Histopathology 1996;28:537-41.

70 Ellis IO, Humphreys S, Michell M, et al. Best Practice No 179. Guidelines for breast needle core biopsy handling and reporting in breast screening assessment. J Clin Pathol 2004;57:897-902.

71 Haybittle JL, Blamey RW, Elston CW, et al. A prognostic index in primary breast cancer. Br J Cancer 1982:45:361-6.

72 Carter CL, Allen C, Henderson DE. Relation of tumour size, lymph node status and survival in 24,740 breast cancer cases. Cancer 1989;63:181-7.

73 Pain JA, Ebbs SR, Hern RP, et al. Assessment of breast cancer size: a comparison of methods. Eur J Surg Oncol 1992;18:44-8.

74 Dillon MF, Quinn CM, McDermott EW, et al. Diagnostic accuracy of core biopsy for ductal carcinoma in situ and its implications for surgical practice. $J$ Clin Pathol 2006:59:740-3.

75 Wahedna Y, Evans AJ, Pinder SE, et al. Mammographic size of ductal carcinoma in situ does not predict the presence of an invasive focus. Eur $J$ Cancer 2001;37:459-62.

76 Yen TW, Hunt KK, Ross MI, et al. Predictors of invasive breast cancer in patients with an initial diagnosis of ductal carcinoma in situ: a guide to selective use of sentinel lymph node biopsy in management of ductal carcinoma in situ. J Am Coll Surg 2005;200:516-26. 
77 Renshaw AA. Predicting invasion in the excision specimen from breast core needle biopsy specimens with only ductal carcinoma in situ. Arch Pathol Lab Med 2002;126:39-41.

78 Rutstein LA, Johnson RR, Poller WR, et al. Predictors of residual invasive disease after core needle biopsy diagnosis of ductal carcinoma in situ. Breast $J$ 2007:13:251-7.

79 Huo L, Sneige N, Hunt KK, et al. Predictors of invasion in patients with coreneedle biopsy-diagnosed ductal carcinoma in situ and recommendations for a selective approach to sentinel lymph node biopsy in ductal carcinoma in situ. Cancer 2006; 107:1760-8.

80 Mendez I, Andreu FJ, Saez E, et al. Ductal carcinoma in situ and atypical ductal hyperplasia of the breast diagnosed at stereotactic core biopsy. Breast $J$ 2001;7:14-8.

81 Hoorntje LE, Schipper ME, Peeters PH, et al. The finding of invasive cancer after a preoperative diagnosis of ductal carcinoma-in-situ: causes of ductal carcinoma-in-situ underestimates with stereotactic 14-gauge needle biopsy. Ann Surg Oncol 2003; 10:748-53.

82 Bagnall MJ, Evans AJ, Wilson AR, et al. Predicting invasion in mammographically detected microcalcification. Clin Radiol 2001;56:828-32.

83 Bonnett M, Wallis T, Rossmann M, et al. Histologic and radiographic analysis of ductal carcinoma in situ diagnosed using stereotactic incisional core breast biopsy. Mod Pathol 2002;15:95-101.

84 Brem RF, Schoonjans JM, Goodman SN, et al. Nonpalpable breast cancer: percutaneous diagnosis with 11-and 8-gauge stereotactic vacuum-assisted biopsy devices. Radiology 2001;219:793-6.

85 King TA, Farr GH Jr, Cederbom GJ, et al. A mass on breast imaging predicts coexisting invasive carcinoma in patients with a core biopsy diagnosis of ductal carcinoma in situ. Am Surg 2001;67:907-12.

86 Houssami N, Ciatto S, Ellis I, et al. Underestimation of malignancy of breast core-needle biopsy: concepts and precise overall and category-specific estimates. Cancer 2007:109:487-95.

87 Iwase T, Takahashi K, Gomi N, et al. Present state of and problems with core needle biopsy for non-palpable breast lesions. Breast Cancer 2006;13:32-7.

88 Patchefsky AS, Schwartz GF, Finkelstein SD, et al. Heterogeneity of intraductal carcinoma of the breast. Cancer 1989;63:731-41.

89 Mittendorf EA, Arciero CA, Gutchell V, et al. Core biopsy diagnosis of ductal carcinoma in situ: an indication for sentinel lymph node biopsy. Curr Surg 2005:62:253-7.

90 Plantade R, Hammou JC, Fighiera M, et al. [Underestimation of breast carcinoma with 11 -gauge stereotactically guided directional vacuum-assisted biopsy]. J Radiol 2004:85:391-401.

91 Harvey JM, Sterrett GF, Frost FA. Atypical ductal hyperplasia and atypia of uncertain significance in core biopsies from mammographically detected lesions: correlation with excision diagnosis. Pathology 2002;34:410-6.

92 Renshaw AA, Cartagena N, Schenkman RH, et al. Atypical ductal hyperplasia in breast core needle biopsies. Correlation of size of the lesion, complete removal of the lesion, and the incidence of carcinoma in follow-up biopsies. Am J Clin Pathol 2001;116:92-6.

93 Ely KA, Carter BA, Jensen RA, et al. Core biopsy of the breast with atypical ductal hyperplasia: a probabilistic approach to reporting. Am J Surg Pathol 2001;25:1017-21.

94 Mokbel K. Treatment of ductal carcinoma in situ of the breast: review of recent advances and future prospects. Int J Fertil Womens Med 2003;48:217-25.

95 Renshaw AA. Minimal ( $<$ or $=0.1 \mathrm{~cm}$ ) invasive carcinoma in breast core needle biopsies. Incidence, sampling, associated findings, and follow-up. Arch Pathol Lab Med 2004; 128:996-9.

96 Pinder SE, Ellis IO, Galea M, et al. Pathological prognostic factors in breast cancer. III. Vascular invasion: relationship with recurrence and survival in a large study with long-term follow-up. Histopathology 1994;24:41-7.
97 Winchester DP, Jeske JM, Goldschmidt RA. The diagnosis and management of ductal carcinoma in-situ of the breast. CA Cancer J Clin 2000;50:184-200.

98 Solin $\mathrm{L}$, Kurtz J, Fourquet A, et al. Fifteen-year results of breast-conserving surgery and definitive breast irradiation for the treatment of ductal carcinoma in situ of the breast. J Clin Oncol 1996;14:754-63.

99 Damera A, Evans AJ, Cornford EJ, et al. Diagnosis of axillary nodal metastases by ultrasound-guided core biopsy in primary operable breast cancer. Br J Cancer 2003;89:1310-3.

100 Newman EL, Kahn A, Diehl KM, et al. Does the method of biopsy affect the incidence of sentinel lymph node metastases? Breast J 2006;12:53-7.

101 Zidan A, Christie Brown JS, Peston D, et al. Oestrogen and progesterone receptor assessment in core biopsy specimens of breast carcinoma. J Clin Pathol 1997;50:27-9.

102 Al Sarakbi W, Salhab M, Thomas V, et al. Is preoperative core biopsy accurate in determining the hormone receptor status in women with invasive breast cancer? Int Semin Surg Oncol 2005;2:15.

103 Nadji M, Gomez-Fernandez C, Ganjei-Azar P, et al. Immunohistochemistry of estrogen and progesterone receptors reconsidered: experience with 5,993 breast cancers. Am J Clin Pathol 2005; 123:21-7.

104 Rhodes A, Jasani B, Barnes DM, et al. Reliability of immunohistochemical demonstration of oestrogen receptors in routine practice: interlaboratory variance in the sensitivity of detection and evaluation of scoring systems. J Clin Pathol 2000;53:125-30.

105 Hodi Z, Chakrabarti J, Lee AH, et al. The reliability of assessment of oestrogen receptor expression on needle core biopsy specimens of invasive carcinomas of the breast. J Clin Pathol 2007;60:299-302.

106 Connor CS, Tawfik OW, Joyce AJ, et al. A comparison of prognostic tumor markers obtained on image-guided breast biopsies and final surgical specimens. Am J Surg 2002;184:322-4.

107 Smyczek-Gargya B, Krainick U, Muller-Schimpfle M, et al. Large-core needle biopsy for diagnosis and treatment of breast lesions. Arch Gynecol Obstet 2002;266: 198-200.

108 Jacobs TW, Siziopikou KP, Prioleau JE, et al. Do prognostic marker studies on core needle biopsy specimens of breast carcinoma accurately reflect the marker status of the tumor? Mod Pathol 1998;11:259-64.

109 Taucher S, Rudas M, Mader RM, et al. Prognostic markers in breast cancer: the reliability of HER2/neu status in core needle biopsy of 325 patients with primary breast cancer. Wien Klin Wochenschr 2004;116:26-31.

110 Pohlodek K, Galbavy S, Bartosova M, et al. Semi-quantitative RT-PCR assessment of molecular markers in breast large-core needle biopsies. Neoplasma 2004:51:415-21.

111 Caramella T, Chapellier C, Ettore F, et al. Value of MRI in the surgical planning of invasive lobular breast carcinoma: a prospective and a retrospective study of 57 cases: comparison with physical examination, conventional imaging, and histology. Clin Imaging 2007;31:155-61.

112 Kepple J, Layeeque R, Klimberg VS, et al. Correlation of magnetic resonance imaging and pathologic size of infiltrating lobular carcinoma of the breast. Am J Surg 2005;190:623-7.

113 Ryden L, Boiesen P, Jonsson PE. Assessment of microvessel density in core needle biopsy specimen in breast cancer. Anticancer Res 2004;24:371-5.

114 Rody A, Karn T, Gatje R, et al. Gene expression profiles of breast cancer obtained from core cut biopsies before neoadjuvant docetaxel, adriamycin, and cyclophoshamide chemotherapy correlate with routine prognostic markers and could be used to identify predictive signatures. Zentralb/ Gynakol 2006; 128:76-81.

115 Pierga JY, Reis-Filho JS, Cleator SJ, et al. Microarray-based comparative genomic hybridisation of breast cancer patients receiving neoadjuvant chemotherapy. Br J Cancer 2007;96:341-51. 